\title{
Method for measuring thermo-emf of a "tool-workpiece" natural thermocouple in chip forming machining
}

\author{
Alexander S. Sergeev ${ }^{1, *}$, Zhanna S. Tikhonova ${ }^{1}$, and Tatiana $V$. Uvarova $^{1}$ \\ ${ }^{1}$ Volgograde State Technical University, Linine Ave. 28, Volgograde 400005, Russia
}

\begin{abstract}
The article presents a new method and a device for measuring the signal of thermoelectromotive force of a "tool - workpiece" natural thermocouple in the chip forming machining during the turning process. It is proposed to use a device of stationary current-collecting connection for fixing and measuring thermo-electromotive force signal, which allows to eliminate the influence of the transient resistance for existing constructions of movable current collectors. This circumstance makes it possible to reduce the measurement error of the signal and at the same time to increase its reliability. The review and analysis of the most similar constructive solutions have been carried out and there are also experimental data values which have been obtained when comparing the proposed device and the prototype.
\end{abstract}

The processes of edge cutting machining of the workpiece with tool material are accompanied by the thermoelectromotive force (thermo-emf) generated by "tool - workpiece" natural thermocouple. It is known that the variation of the thermo-emf signal is observed due to the change in the work of the electrons liberation from the hard alloy and the processed workpiece. The value of the contact component for the thermo-emf signal of the tool-workpiece pair will be determined from the condition of equalizing the electrons electrochemical potentials. This fact gives the opportunity to use thermo-emf signal of a "tool workpiece" as a diagnostic parameter for evaluating physico-mechanical properties of various combinations of "tool-workpiece" contact pairs for subsequent assignment and optimization of the cutting modes while processing the same workpiece with the given tool. And for this purpose, thermo-emf signal should be obtained on strictly defined test run modes, which are the same for all groups of processed and tool materials.

Using the informative ability of the cutting thermoemf signal to ensure the reliability for the automated determination of the edge cutting modes is presented in many scientific works, in particular in [1-5].

In addition to the occurrence of a parasitic component in the signal and the need for electrical insulation of the tool and the steel workpiece, the main disadvantage of thermo-emf signal application is the dependence of the transient resistance and hence, the value of the thermo-emf on the structure and type of the current collectors installed on the machine tool spindle units. Thus, the main way to increase the reliability level of the thermo-emf signal, and consequently, the reliability of the automated determination of cutting modes, is the development of a method for picking up the thermo-emf signal without the use of movable current collectors of the contact type. Let us consider the best known methods for measuring the cutting thermoemf signal.

There is a method for measuring the cutting EMF [6], in which a tool or a workpiece is isolated from the machine tool mass, then the tool and the workpiece are brought into complete electrical circuit and the cutting EMF generated on the contact surfaces of the tool is registered. The whole working section of the tool, excluding the zones in which the cutting EMF is measured, should be coated with a dielectric wearresistant layer.

This well-known method has some disadvantages. When the tool is isolated from the machine tool mass it is necessary to spread dielectric wear-resistant coating over all the cutting tool elements involved in the machining but it greatly increases the production cost and reduces its productivity.

In the case of the workpiece insulation from the machine tool mass, this method involves the use of a current collector on the side of the machine spindle unit, which reduces the reliability of the measured cutting EMF due to electrical losses at the coupling sites between the current collector contacts and the bearing part of the machine spindle during its rotation at different frequencies.

Another well-known method for measuring the cutting EMF is described in the work [7]. This method provides the opportunity of measuring the variable component in the cutting EMF signal, which is picked up by a current collector device, while isolating the cutting tool and the workpiece from the machine tool mass.

The drawback of this method [7] is that the use of the current collector device reduces the reliability of the cutting EMF signal and also reduces the equipment

\footnotetext{
* Corresponding author: sergeevapp@,mail.ru
} 
versatility when this method of EMF measurement is industrially introduced.

The most similar procedure for the same purpose is a method for measuring the thermo-emf of a "toolworkpiece" natural thermocouple [8]. It involves preliminary thermo-emf measurement of a "toolworkpiece" natural thermocouple in chip forming machining in the speed range above the build-up forming zone at idle speed of the machine, while measuring the resistance of the oil films of the machine bearings. At the resistance value equal to or more than $100 \mathrm{ohms}$, it is necessary to record a useful thermo-emf signal of operating cutting modes using a peak detector as a filter for separating parasitic thermo-emf, also fixing the cutting torque which is characterized by the onset of stable chip formation.

The disadvantage of the given method [8] is that it requires measuring the resistance of the oil films in the machine bearings, which is quite unstable and fluctuates over a wide range, but the method does not specify how to register the useful thermo-emf signal if the resistance of the oil films of the machine bearings is less than 100 ohms. In addition, this method involves the use of a graphite current collector on the side of the machine spindle unit, which reduces the reliability of the measured thermo-emf signal due to electrical losses at the coupling sites between the current collector contacts and the measuring flange of the machine spindle.

In this regard, the authors propose a new technical solution to reduce an error in measuring the useful thermo-emf signal by including an isolated tool and a workpiece in a complete electrical circuit without using intermediate members for fixing the electrical signal (current collectors of various designs).

The technical result that can be obtained by the implementation of the proposed technical solution consists in the accuracy measurement increase of the useful thermo-emf signal of a natural thermocouple, which enhances technological application of the informative ability of the thermo-emf signal in a "toolworkpiece" contact pair.

The given technical result is achieved by the fact that in order to increase the measurement accuracy of the useful thermo-emf signal that is produced during the cutting operation, the measurement of this signal should be made with respect to the insulated non-conductive shims of the cutting tool and the grounded body of the machine tool. The workpiece relative to the machine body is not additionally isolated, and the current collector in the measurement scheme is not applied.

In the proposed method of measuring the thermo-emf of a "tool-workpiece" natural thermocouple we should use complete electrical insulation of the tool by nonconductive shims rather than the parts of oil films in the machine bearings. It allows to significantly reduce the distortions of the useful thermo-emf signal due to constant dielectric properties of non-current conducting shims, in contrast to the changing resistance level of machine oil films [8]. The stiffness of the MFTW system embedded in the machine tool design and the level of vibration resistance must be maintained.
In this case, a mobile current collector (see prototype [8]) is not used, and a peak detector (amplitude rectifier) is directly connected to the grounded body of the machine tool, thus reducing the measurement error of the thermo-emf signal by eliminating electrical losses at the coupling sites between the current collector contacts and the measuring flange of the machine tool spindle.

The main point of the technical solution is explained by the scheme for the thermo-emf measurement of a natural thermocouple on a lathe (Figure 1). The workpiece 1 is fixed in the jaw-chuck of the machine tool. The cutting is carried out in cantilever or with the pressing by the rear center support. 3 . The cutter 2 is fixed in the tool holder and is additionally electrically isolated by non-conductive shims 4 . Metal cutting is performed in the speed range above the build-up forming zone and the thermo-emf of the "tool-workpiece" natural thermocouple is measured during the chip forming machining by a millivoltmeter 6 with the help of the peak detector circuit (amplitude rectifier) 5 connected on one side to the cutting tool body 2 , and on the other side to the grounded body of the machine tool.

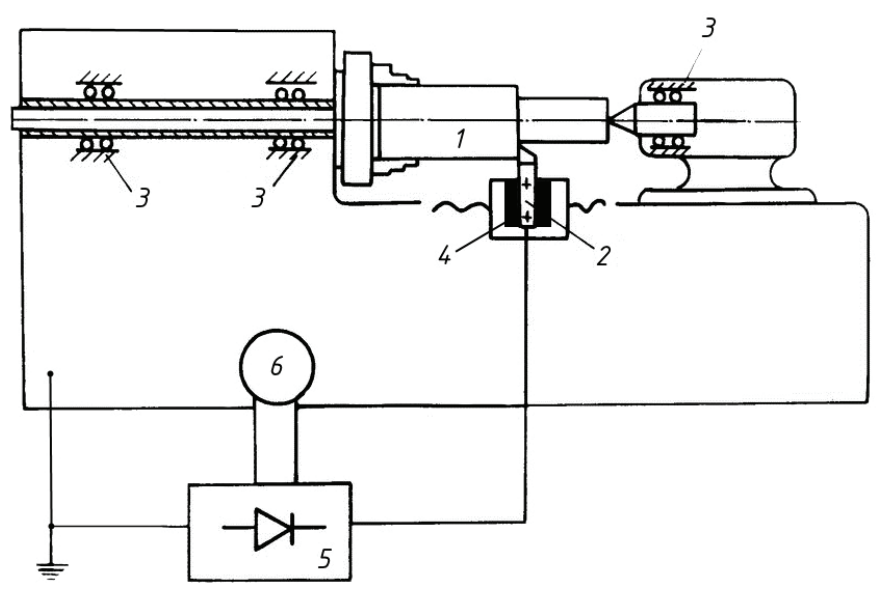

Fig. 1. Thermo-emf signal measuring scheme.

The process is carried out in the following way. Preliminary, at a selected speed corresponding to the range above the build-up forming zone, a metal workpiece fixed directly to the machine is processed with a tool fastened with non-conductive shims. A peak detector (amplitude rectifier) connected in the circuit between the recording device and the thermo-emf source of a natural thermocouple is used as a filter for clearing the parasitic thermo-emf interference. The registration of the useful thermo-emf signal of a natural thermocouple is carried out from the initial moment of cutting until the emergence of a stable constant value on the recording instrument for 4-5 seconds. The storage period of the registered level of the useful thermo-emf signal is determined by condenser capacity which is mounted at the output of the peak detector.

Table 1 shows the results of the experimental verification of the proposed method for measuring the thermo-emf of a "tool-workpiece" natural thermocouple when metal machining on a $1 \mathrm{~K} 62$ lathe with a carbide tool, at the cutting speed range above the build-up forming zone, using the electrical insulation of the tool. 
Table 1. The results of the experimental verification and comparison with the prototype.

\begin{tabular}{|c|c|c|c|c|c|c|c|c|c|c|c|c|c|c|}
\hline \multirow{6}{*}{ № } & \multirow{6}{*}{ 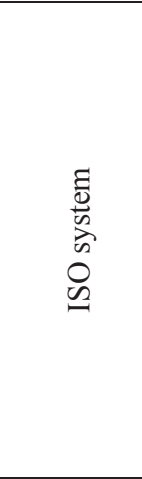 } & \multicolumn{2}{|c|}{$\begin{array}{l}\text { Tool brand and } \\
\text { type }\end{array}$} & \multirow{6}{*}{$\begin{array}{c}\text { Reference } \\
\text { thermo-emf } \\
\text { signal } \\
\text { measurement } \\
E, \mathrm{mV}\end{array}$} & \multicolumn{10}{|c|}{ Thermo-emf signal measurement of a natural thermocouple } \\
\hline & & \multirow{5}{*}{ 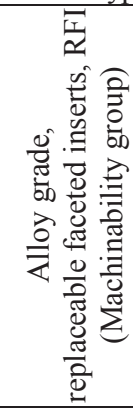 } & \multirow{5}{*}{ 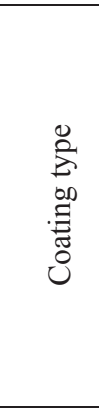 } & & \multicolumn{6}{|c|}{ Method (prototype) [8] } & \multirow{2}{*}{\multicolumn{4}{|c|}{$\begin{array}{c}\text { Proposed method } \\
\text { Tool is insulated, current } \\
\text { collector is not used }\end{array}$}} \\
\hline & & & & & \multicolumn{6}{|c|}{ Tool is insulated, current collector is used } & & & & \\
\hline & & & & & \multirow{2}{*}{\multicolumn{2}{|c|}{$\begin{array}{c}\text { Workpiece } \\
\text { supported } \\
\text { as a } \\
\text { cantilever } \\
\text { without } \\
\text { insulation }\end{array}$}} & \multicolumn{4}{|c|}{$\begin{array}{l}\text { Workpiece is fixed with the } \\
\text { support of the rear center }\end{array}$} & \multirow{2}{*}{\multicolumn{2}{|c|}{$\begin{array}{l}\text { Workpiece } \\
\text { supported as a } \\
\text { cantilever }\end{array}$}} & \multirow{2}{*}{\multicolumn{2}{|c|}{$\begin{array}{l}\text { Workpiece } \\
\text { is fixed } \\
\text { with the } \\
\text { support of } \\
\text { the rear } \\
\text { center }\end{array}$}} \\
\hline & & & & & & & \multicolumn{2}{|c|}{$\begin{array}{l}\text { Workpiece } \\
\text { is not } \\
\text { insulated }\end{array}$} & \multicolumn{2}{|c|}{$\begin{array}{l}\text { Workpiece } \\
\text { is insulated }\end{array}$} & & & & \\
\hline & & & & & $\begin{array}{c}E_{a b}, \\
\mathrm{mV}\end{array}$ & $\begin{array}{l}\delta \\
\%\end{array}$ & $\begin{array}{l}E_{a b} \\
\mathrm{mV}\end{array}$ & $\begin{array}{l}\delta \\
\%\end{array}$ & $\begin{array}{l}E_{b d} \\
\mathrm{mV}\end{array}$ & $\begin{array}{l}\delta \\
\%\end{array}$ & $\begin{array}{l}E_{b c}, \\
\mathrm{mV}\end{array}$ & $\delta, \%$ & $\begin{array}{l}E_{b c} \\
\mathrm{mV}\end{array}$ & $\begin{array}{l}\delta \\
\%\end{array}$ \\
\hline 1 & $\begin{array}{l}\text { SNMA } \\
120408\end{array}$ & $\begin{array}{l}\text { BK6 } \\
(\mathrm{K} 20)\end{array}$ & - & 8,5 & 7,9 & 7,1 & 8,2 & 3,5 & 7,7 & 9,4 & 8,3 & 2,4 & 8,4 & 1,2 \\
\hline 2 & $\begin{array}{l}\text { SNMA } \\
120408\end{array}$ & $\begin{array}{c}\mathrm{BK} 6 \\
(\mathrm{~K} 20)\end{array}$ & TiN & 12,2 & 12,8 & $-4,9$ & 12 & 1,6 & 12,5 & $-2,5$ & 12,2 & 0 & 12,1 & 0,8 \\
\hline 3 & $\begin{array}{l}\text { TCMW } \\
110204\end{array}$ & $\begin{array}{c}\mathrm{BK} 8 \\
(\mathrm{M} 30)\end{array}$ & - & 7,4 & 7,2 & 2,7 & 7,7 & $-4,1$ & 7,1 & 4,05 & 7,2 & 2,7 & 7,5 & $-1,4$ \\
\hline 4 & $\begin{array}{l}\text { WCMT } \\
080408\end{array}$ & $\begin{array}{l}\text { T15K6 } \\
(\mathrm{P} 10)\end{array}$ & - & 11,9 & 12,2 & $-2,5$ & 12,1 & $-1,7$ & 12,2 & $-2,5$ & 11,8 & 0,8 & 11,8 & 0,8 \\
\hline 5 & $\begin{array}{l}\text { WCMT } \\
080408 \\
\end{array}$ & $\begin{array}{l}\text { T15K6 } \\
(\mathrm{P} 10)\end{array}$ & TiN & 12,7 & 11,6 & 8,7 & 11,8 & 7,1 & 11,6 & 8,7 & 12,4 & 2,4 & 12,5 & 1,6 \\
\hline 6 & $\begin{array}{l}\text { WCMT } \\
080408\end{array}$ & $\begin{array}{l}\text { T15K6 } \\
(\mathrm{P} 10)\end{array}$ & $\mathrm{TiCN}$ & 12,2 & 11,9 & 2,5 & 11,8 & 3,3 & 11,8 & 3,3 & 12,2 & 0,0 & 12,1 & 0,8 \\
\hline 7 & $\begin{array}{l}\text { SCMT } \\
120408\end{array}$ & $\begin{array}{l}\text { TH20 } \\
\text { (P01) }\end{array}$ & - & 7,4 & 7,6 & $-2,7$ & 7,6 & $-2,7$ & 7,2 & 2,7 & 7,3 & 1,4 & 7,5 & $-1,4$ \\
\hline 8 & $\begin{array}{l}\text { SCMT } \\
120408 \\
\end{array}$ & $\begin{array}{l}\text { TH20 } \\
(\mathrm{P} 01)\end{array}$ & TiAlN & 7,5 & 7,2 & 4,0 & 7,3 & 2,7 & 7,3 & 2,7 & 7,4 & 1,3 & 7,4 & 1,3 \\
\hline 9 & $\begin{array}{l}\text { SPUN } \\
120308 \\
\end{array}$ & $\begin{array}{c}\text { T5K10 } \\
(\mathrm{P} 30)\end{array}$ & - & 14,6 & 14,7 & $-0,7$ & 14,7 & $-0,7$ & 14,8 & $-1,4$ & 14,4 & 1,4 & 14,4 & 1,4 \\
\hline 10 & $\begin{array}{c}\text { SPUN } \\
120308\end{array}$ & $\begin{array}{c}\text { T5K10 } \\
(\mathrm{P} 30)\end{array}$ & - & 15,4 & 15,4 & 0,0 & 15,9 & $-3,2$ & 15,3 & 0,6 & 15,2 & 1,3 & 15,3 & 0,6 \\
\hline 11 & $\begin{array}{c}\text { CNMG } \\
120408- \\
\text { PM 4225 } \\
\end{array}$ & $\begin{array}{c}\text { GC } \\
4225\end{array}$ & TiN & 10,7 & 11,5 & $-7,5$ & 10,8 & $-0,9$ & 11 & $-2,8$ & 10,5 & 1,9 & 10,8 & $-0,9$ \\
\hline 12 & $\begin{array}{c}\text { CNMG } \\
120408- \\
\text { PM 4225 } \\
\end{array}$ & $\begin{array}{c}\text { GC } \\
4225\end{array}$ & TiN & 11,6 & 11,4 & 1,7 & 11,8 & $-1,7$ & 11,2 & 3,4 & 11,9 & $-2,6$ & 11,7 & $-0,9$ \\
\hline 13 & $\begin{array}{c}\text { TPUN } \\
110304 \\
\end{array}$ & $\begin{array}{c}\text { TT7K12 } \\
\text { (P40) }\end{array}$ & - & 9,2 & 9,7 & $-5,4$ & 9,5 & $-3,3$ & 8,7 & 5,4 & 9 & 2,2 & 9,1 & 1,1 \\
\hline 14 & $\begin{array}{l}\text { TCMT } \\
\text { 16T308E- } \\
\text { UR } \\
\end{array}$ & $\begin{array}{c}\text { T30K4 } \\
\text { (P01) }\end{array}$ & TiN & 9,5 & 9,4 & 1,1 & 9,2 & 3,2 & 9,2 & 3,2 & 9,6 & $-1,1$ & 9,6 & $-1,1$ \\
\hline & Average v & e of the 1 & lative er & $\delta_{\mathrm{av}}, \%$ & 3 & & 2 & & 3 & & & & 0 & \\
\hline
\end{tabular}

It also presents the comparative analysis of the given method with the prototype [8]. The following are the cemented carbide tools used for the experiment: BK6, BK8， T5K10， T15K6， T30K4， ТН20, ТT7K12. The cemented carbide cutting tools come under the Russian Standard (GOST) 2209-69, which are bolted or fixed mechanically to the tool holder. Under the International Standard Organization's classifications, the tools listed above have equivalents in the ranges that consist of K20, $\mathrm{M} 30, \mathrm{P} 10, \mathrm{P} 30, \mathrm{P} 01$ and P40 (ISO 2004). The measurement and fixation of the thermo-emf signal used for the relative comparison of the readings was carried out according to the scheme in figure 2. The workpiece (disk) 1 is fixed with a nut 7 on a special mandrel which is isolated from the chuck cams 6 with non-conductive shims 2 . The diameter of the workpiece 1 is about 300 $\mathrm{mm}$, which allows to use the minimum spindle speed 9 and directly register the signal from the shielded cable 4. The cutting tool 3 is also isolated from the body of the lathe tool holder 15 by means of non-current conducting shims. The signal is transferred from the workpiece 1 through the nut 7 and the shielded cable 4 to one of the digital millivoltmeter inputs, the second input of the digital millivoltmeter accepts the signal from the cutting tool 3 via the shielded cable 16. The complete electrical circuit of the natural thermocouple is completely isolated from the machine body by means of non-current conductive shims on the side of the cutting tool 3 and the workpiece 1 . In this case the thermo-emf signal (see figure 2) is transmitted from the workpiece 1 through the bearing assemblies 5, 11, 12 of the machine spindle unit, the gearing of the transmission 8,14 , the change gear bracket, the feed shaft (or the feedscrew) 
13 and the machine rear center (in the case of rear center support machining) to the machine body 10 due to the formation of electrically conductive oil films in the conjunctions spots of the mating units of the machine during the mechanical energy transfer [9].

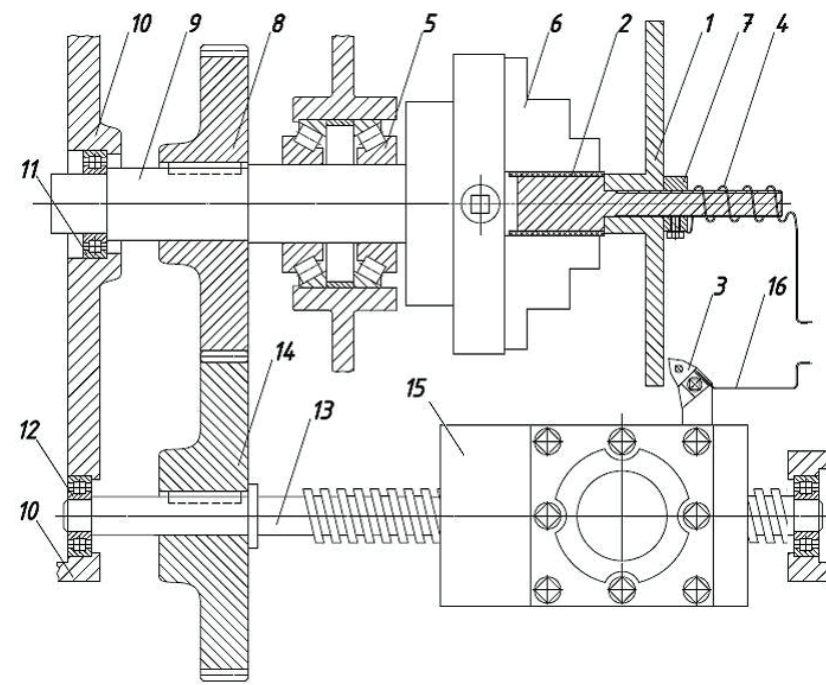

Fig. 2. Measurement and fixation scheme of the thermo-emf signal used for relative comparison of the indications.

The process of generating useful thermo-emf signal was recorded by means of a digital millivoltmeter. The processed metal is $40 \mathrm{X}$ steel, the tool is a replaceable faceted non-re-sharpened hard alloy inserts of various grades, type of coating and geometry (see Table 1).

The error in measuring the thermo-emf signal was estimated from the average value of the relative error Sav. Fig. 3 shows the comparison of the indicators average values of the relative measuring error in the thermo-emf signal between the prototype and the method proposed by the authors.

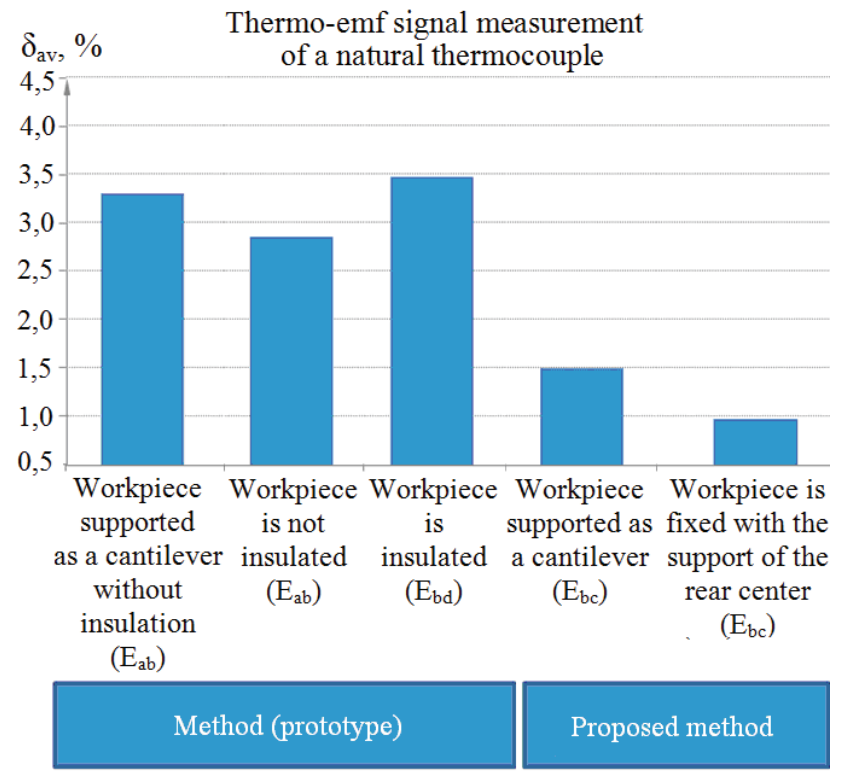

Fig. 3. Comparison of the $\delta_{\text {av }}$ measurements of the thermo-emf signal.
Figure 4 shows the location of the measurement points (cold junction points) of the thermo-emf value for a "processed workpiece-tool" natural thermocouple in chip forming machining. In Figure 4 and Table 1, the measured values of the thermo-emf are represented in the form, for example, $E_{a b}=12.1 \mathrm{~V}$, which means that the signal of $12.1 \mathrm{~V}$ amplitude was measured between point a (current collector output) and point $b$ (cutting edge of the cutting tool).

Thus, it is possible to register the reference value of the thermo-emf signal which is used in the further comparison of the proposed method and the prototype (see Table 1).

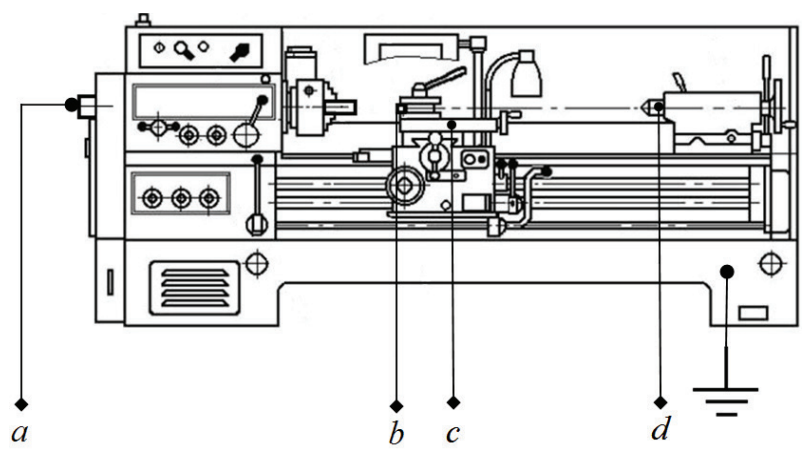

Fig. 4. Arrangement scheme of measurement points for the thermo-emf value.

The proposed method provides accurate measurement of the useful thermo-emf signal of a natural thermocouple and can be applied in the automatic thermo-emf measurement mode, for example, programmatically on $\mathrm{CNC}$ machines where the time of measurement, storage and reset of the signal can be set by a timer. The implementation of the proposed method allows to intensify the measurement accuracy of the useful thermo-emf signal of a natural thermocouple (see Table 1), which increases the reliability and enhances the technological possibility of using the informative ability of the thermo-emf signal of the "tool-workpiece" contact pair [1-5].

\section{References}

1. A.L. Plotnikov, A. S. Sergeev, N. G. Zaytseva, Use of the informative ability of a natural thermocouple signal to ensure the reliability of automated determination of edge cutting machining. Science based technologies in machine building, № 5, pp. 35-40 (2013)

2. A.L. Plotnikov, V.A. Kamayev, A.S. Sergeyev, T.V. Uvarova, Modernisation of universal lathes and their operating systems in order to increase their work efficiency, News of VSTU. Ser. Actual problems of the control, computer technology and computer science in technical systems, Volgograd, № 11 (190), pp. 61-66 (2016)

3. A.L. Plotnikov, A.S. Sergeyev, T.V. Uvarova, N.G. Zaytseva, Cutting force calculation and back calculating of the tool life for three stages of 
turning corrosion-resistant steels, Certificate of the state registration of the software program № 2015619947, 17.09.15 RF, IPC (no). VSTU (2015)

4. E.G. Krylov, A.U. Gorelova, A.S. Sergeev, The way to control the condition of the cutting edges of prefabricated multiblade tools. Patent RF, no. 2496629 IPC, B23Q17/09, VSTU (2013)

5. A.L. Plotnikov, A.S. Sergeev, Zh.S. Tikhonova, Pecularities of the use of cutting EMF signal in automated machine tool manufacturing, Science based technologies in machine building, № 6, pp. 21-27 (2016)

6. V.I. Aleksandrov, A.G. Borodayev, E.I. Glinkin, Cutting EMF signal measurement method, Patent RF, no. 2149745, IPC 7 V23 Q17 / 09, TSTU (2000)

7. S.V. Vasil'yev, EMF and cutting temperature. Machine tools and instruments, №10, pp. 20-22 (1980)

8. A.L. Plotnikov, Measuring method for the thermoelectric power of a tool - workpiece natural thermocouple, Patent RF, no. 2117557, IPC 7 V23 V25 / 06, VSTU (1999)

9. Y. A.Mit'kin, Electrophysical characteristics of liquid dielectrics containing impurities: tutorial (Ivanovo State Power University, Ivanovo, 2002) 